\title{
Correlation Between Dynamic Compressive Strength and Fracture Behaviors of Bulk Metallic Glasses
}

\author{
Wenqing $\mathrm{Li}^{1,2}$ - Zhengwang $\mathrm{Zhu}^{1} \cdot$ Guojie $\mathrm{Li}^{3}$ · Long Zhang ${ }^{1} \cdot$ Zhengkun $\mathrm{Li}^{1} \cdot$ Huameng $\mathrm{Fu}^{1} \cdot \mathrm{Hong}$ wei Zhang ${ }^{1}$. \\ Hong $\mathrm{Li}^{1} \cdot$ Aimin Wang ${ }^{1} \cdot$ Haifeng Zhang ${ }^{1}$
}

Received: 8 February 2020 / Revised: 19 March 2020 / Published online: 15 May 2020

(c) The Chinese Society for Metals (CSM) and Springer-Verlag GmbH Germany, part of Springer Nature 2020

\begin{abstract}
The mechanical behaviors of $\mathrm{Zr}_{43.5} \mathrm{Cu}_{43.5} \mathrm{Ni}_{4} \mathrm{Al}_{8} \mathrm{Nb}_{1}, \mathrm{Zr}_{55.4} \mathrm{Cu}_{31.6} \mathrm{Ni}_{4} \mathrm{Al}_{8} \mathrm{Nb}_{1}, \mathrm{Ti}_{32.8} \mathrm{Zr}_{30.2} \mathrm{Ni}_{5.3} \mathrm{Cu}_{9} \mathrm{Be}_{22.7}$ (at.\%) metallic glass at different strain rates were studied. For all the present alloys, the dispersion over $700 \mathrm{MPa}$ was observed on the strength in the repeated dynamic compressions, which was much stronger than that of the quasi-static compressive strength. Such the dispersion of the dynamic compressive strength was well correlated with the corresponding fracture behaviors. The area of fracture surface was calculated and also showed a strong dispersion for all the fractured specimens tested at the strain rate of $500 \mathrm{~s}^{-1}$ and $1000 \mathrm{~s}^{-1}$. All the specimens showed a linear relationship between the square of dynamic compressive strength and the area of fracture surface in the dynamic compression tests. This phenomenon was mainly thought to be related to the difference of mean initial free volume concentration of different samples, stress concentration caused by the split Hopkinson pressure bar experimental setup and high sensitivity of defects under dynamic deformation. These findings were beneficial to deeply understand the effect of strain rate on the mechanical properties of the metallic glass.
\end{abstract}

Keywords Metallic glass $\cdot$ Dynamic compression $\cdot$ Weibull statistics $\cdot$ Shear bands

\section{Introduction}

Bulk metallic glasses (BMGs) have attracted increasing attention because of their superior mechanical, physical, chemical and biological properties, etc. [1-5]. High mechanical performance including high strength, high elastic limit and high toughness, etc., makes BMGs and BMG matrix composites potentially prosperous engineering structural materials $[1,4]$, especially in some impacting events, i.e.,

Available online at http://link.springer.com/journal/40195.

Zhengwang Zhu

zwzhu@imr.ac.cn

Haifeng Zhang

hfzhang@imr.ac.cn

1 Shenyang National Laboratory for Materials Science, Institute of Metal Research, Chinese Academy of Sciences, Shenyang 110016, China

2 School of Materials Science and Engineering, University of Science and Technology of China, Hefei 230026, China

3 Beijing Institute of Space Long March Vehicle, Beijing 10076, China defense, aerospace and micro-electro-mechanical system (MEMS) fields [6-9]. Accordingly, it is urgent to recognize the deformation behaviors at high strain rate and figure out the underlying mechanism for promoting BMGs practical applications and developing new BMG materials with the optimized performance.

Many works have devoted to exploring the dynamic mechanical behaviors of BMG materials [10-12]. The effects of the strain rate [13-16], aspect ratio (i.e., $L / D$ ) [17-19], loading conditions [20-23], etc., have been studied for BMGs with different nominal compositions. However, some controversy has occurred in the reported works up to now. For example, the independence of strength on the strain rate was reported for the Vit $1 \mathrm{BMG}$ $\left(\mathrm{Zr}_{41.25} \mathrm{Ti}_{13.75} \mathrm{Cu}_{12.5} \mathrm{Ni}_{10} \mathrm{Be}_{22.5}\right)$ by Subhash et al. [14] and Bruck et al. [24], and contrarily, the effect of strain rate on the strength is negative for the same alloy reported by Sunny et al. [19]. Meanwhile, the strength displayed the negative effect of strain rate for the $\mathrm{Zr}_{55} \mathrm{Cu}_{30} \mathrm{Al}_{10} \mathrm{Ni}_{5}$ [25], $\mathrm{Zr}_{57} \mathrm{Ti}_{5} \mathrm{Cu}_{20} \mathrm{Ni}_{8} \mathrm{Al}_{10}$ [16] and $\mathrm{Zr}_{65} \mathrm{Cu}_{18} \mathrm{Ni}_{7} \mathrm{Al}_{10}$ [26], $\mathrm{Zr}_{50} \mathrm{Cu}_{40} \mathrm{Al}_{10}$ [27] MG alloys. Similarly, it was found out that the fracture behaviors exhibited the several different ways for the same alloy under the dynamic compression 
condition. For the Vit $1 \mathrm{BMG}$ alloy, the fracture angle was measured to be $45^{\circ}$ [24], which is consistent with that of the maximum shear surface, but it was indicated to about $50^{\circ}$ in the high-speed photography [19]. For the other BMG alloys, the fracture angle was reported to vary in the certain range, i.e., $30^{\circ}-76^{\circ}$ for the $\mathrm{Zr}_{55} \mathrm{Cu}_{30} \mathrm{Al}_{10} \mathrm{Ni}_{5}$ alloy [13, 14, $25]$. All these results show that the dispersion of experimental results exists in the dynamic compression experiments, which is probably believed a basic feature of such the measurements. Nevertheless, it is worth noting that the presence of results dispersion makes the analysis of dimensional and strain rate effects more complex and even impossible to separate the effects of several factors as well as the underlying mechanisms.

In the present work, we focused on the above issue. We selected three Zr-based BMG alloys and conducted the quasi-static and dynamic compression tests. Fracture behaviors were studied in detail. It was found out that the dispersion of dynamic compressive strength existed at the similar strain rate, but the dynamic compressive strength was well correlated with the fracture behaviors at the similar strain rate for the current three BMG alloys. It was well understood from the viewpoint of the free volume model and the fracture mechanics.

\section{Materials and Methods}

The ingots with the nominal composition of $\mathrm{Zr}_{43.5} \mathrm{Cu}_{43.5} \mathrm{Ni}_{4} \mathrm{Al}_{8} \mathrm{Nb}_{1}, \quad \mathrm{Zr}_{55.4} \mathrm{Cu}_{31.6} \mathrm{Ni}_{4} \mathrm{Al}_{8} \mathrm{Nb}_{1}$ and $\mathrm{Ti}_{32.8} \mathrm{Zr}_{30.2} \mathrm{Ni}_{5.3} \mathrm{Cu}_{9} \mathrm{Be}_{22.7}$ (in atomic percentage, at.\%, denoted as Z43, Z55 and T33, respectively) were prepared by arc-melting the mixtures of the element metals under a Ti-gettered argon atmosphere. The element metal has purity as high as $99.9 \%$. The chemical homogeneity was obtained by re-melting at least four times. The as-cast samples with a diameter of $4 \mathrm{~mm}$ and a length of $60 \mathrm{~mm}$ were prepared using the copper-mold tilting casting method. The microstructures of the samples were characterized by X-ray diffraction (XRD; Rigaku D/max 2400, Japan, $\mathrm{Cu}-K \alpha$ ). Thermal properties concerning glass transition and crystallization were examined with differential scanning calorimetry (DSC; Netzsch 204F) in a flowing argon atmosphere at a heating rate of $20 \mathrm{~K} / \mathrm{min}$. For each alloy, three identical bars were cast using the same preparation process, which have confirmed its amorphous nature and were used to characterize the compression deformation behavior at three strain rates, respectively. The specimens with $4 \mathrm{~mm}$ (diameter) $\times 4 \mathrm{~mm}$ (length) used for mechanical tests were cut from the as-cast samples. All the specimens were mechanically polished up to No. $2000 \mathrm{SiC}$ paper with the ends carefully ensured to be parallel. The quasi-static compression tests were carried out on an electronic universal testing machine (Instron 5582) at a strain rate of $5 \times 10^{-4} \mathrm{~s}^{-1}$, and the dynamic compression tests were carried out on a split Hopkinson pressure bar (SHPB) apparatus at various strain rates of $500 \mathrm{~s}^{-1}$ and $1000 \mathrm{~s}^{-1}$. A special stopper ring [28], as schematically illustrated in Fig. 1, was designed to ensure that the sample was placed in the center of the rod and to restrict the deformation amount of the sample under dynamic loading. The specially designed copper slices were used as pulse shapers to achieve dynamic compression loading with the constant strain rate. The fractured specimens were observed using a scanning electron microscope (SEM; FEI Quanta 600).

\section{Results and Discussion}

\subsection{Microstructure and Mechanical Properties}

\subsubsection{Microstructure}

Figure 2 shows the XRD patterns of the as-cast samples. All the patterns display only broad peaks, indicating no distinct crystalline phase, but fully amorphous nature is present for the as-cast samples. The amorphous nature was also confirmed by DSC measurements (not shown here). All the as-cast samples showed an apparent glass transition phenomenon, followed by intense crystallization behaviors. The glass transition temperature $\left(T_{\mathrm{g}}\right)$ and onset crystallization temperature $\left(T_{\mathrm{x}}\right)$ were measured to be approximately $733 \mathrm{~K}$, $783 \mathrm{~K}$ for Z43, $688 \mathrm{~K}, 757 \mathrm{~K}$ for Z55 and $611 \mathrm{~K}, 655 \mathrm{~K}$ T33, respectively.

\subsubsection{Quasi-Static Compressive Stress-Strain Relationship}

The quasi-static mechanical properties were firstly measured for all the current BMGs. Figure 3 shows the typical compressive strain-stress curves obtained at a strain rate of
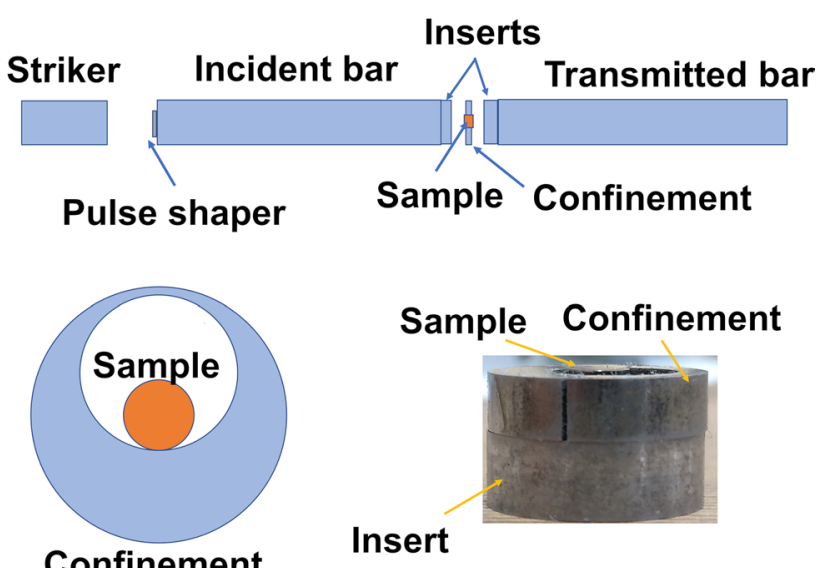

Sample Confinement

Confinement

Insert

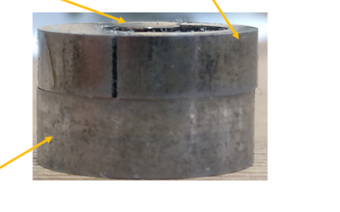

Fig. 1 Schematic illustration of the SHPB apparatus 


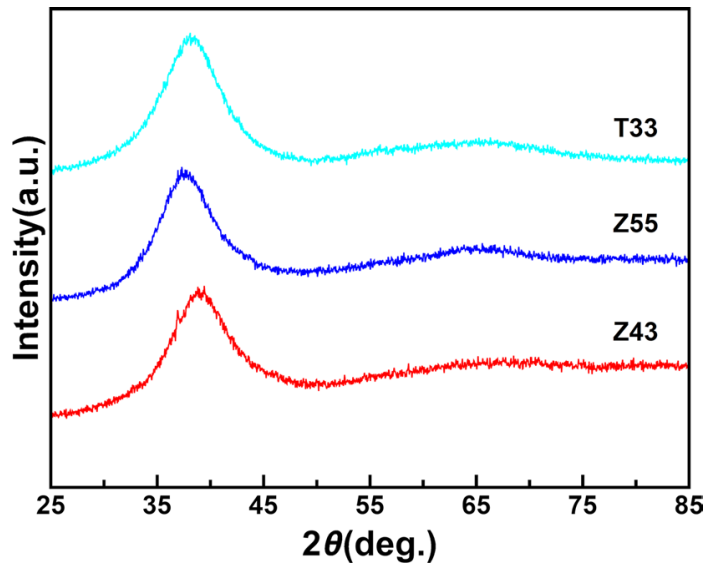

Fig. 2 XRD patterns of the as-cast samples

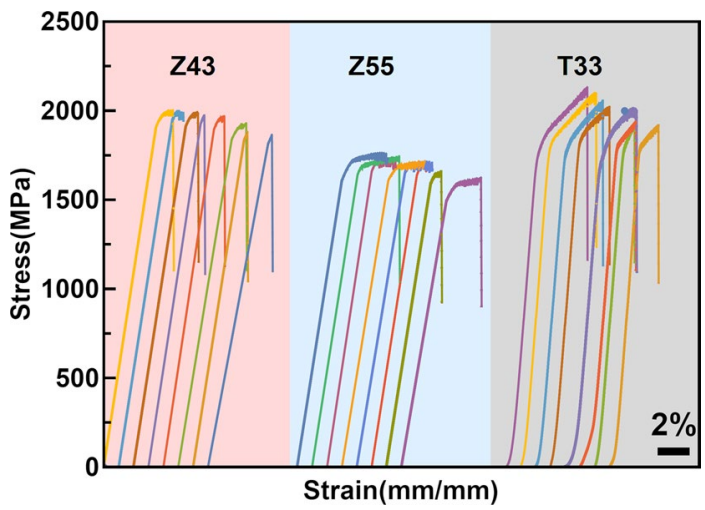

Fig. 3 Typical compressive strain-stress curves for the Z43, Z55 and T33 BMGs at the strain rate of $5 \times 10^{-4} \mathrm{~s}^{-1}$

$5 \times 10^{-4} \mathrm{~s}^{-1}$. At least ten specimens were tested for all the three BMG alloys. For each alloy, all the specimens showed similar deformation behaviors. The specimens elastically deformed in the beginning under compressive loading, yielded about at $1920 \mathrm{MPa}, 1710 \mathrm{MPa}$ and $1830 \mathrm{MPa}$ for Z43, Z55 and T33, respectively, deformed by a little plastic strain before the final fracture. Of the three alloys, the T33 alloy exhibits the best plastic deformation capacity by an indication of $5-7 \%$ plastic strain. A scatter of the strength within $200 \mathrm{MPa}$ is present for the three studied alloys under the quasi-static compression tests.

\subsubsection{Dynamic Compressive Stress-Strain Relationship}

The dynamic compressive mechanical properties were tested for the current three alloys at the strain rate of $500 \mathrm{~s}^{-1}$ and $1000 \mathrm{~s}^{-1}$. Tens of specimens were repeated for each experimental condition. The typical dynamic stress-strain curves are shown in Fig. 4. It is clearly seen that all the alloys display the mechanical behavior of brittle fracture with no plastic deformation at the dynamic compression. Meanwhile, a strong scatter is present for all the alloys at both the tested strain rates. The range of strength variation is measured to be about $1000 \mathrm{MPa}$ for Z43, $800 \mathrm{MPa}$ and $700 \mathrm{MPa}$ for Z55 and T33, which is larger than those obtained in the quasistatic mechanical tests. Such the strong scatter of dynamic compressive strength would contribute to the different interpretation of the experimental results $[14,15,25]$, which is thought to be the origin of some controversy reported so far $[13,25]$.

\subsubsection{Weibull Statistics of Strength}

To further characterize the variation of maximum strength with the strain rate, the relationship of the maximum strength normalized with the quasi-static one with the strain rate is shown in Fig. 5a. The normalized strength obtained at the strain rate of $500 \mathrm{~s}^{-1}$ and $1000 \mathrm{~s}^{-1}$ is in a wide band zone, which increases from 0.5 to 0.9 . With increasing dynamic strain rate, the width of band zone is similar. (a)

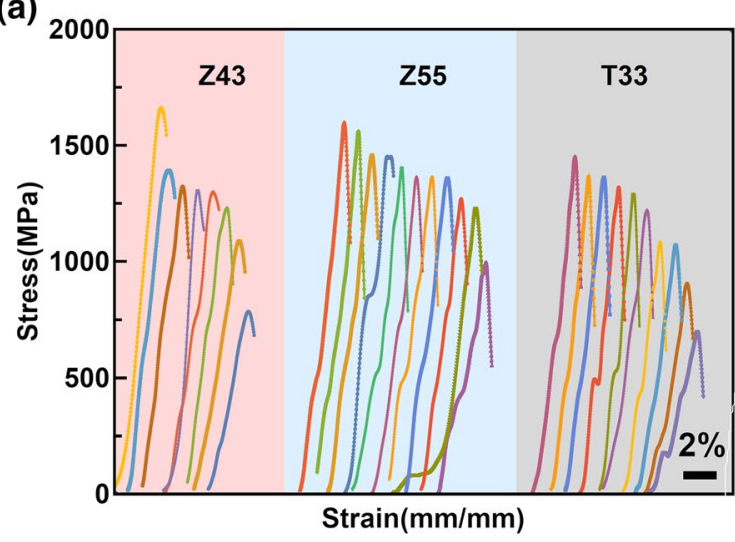

(b)

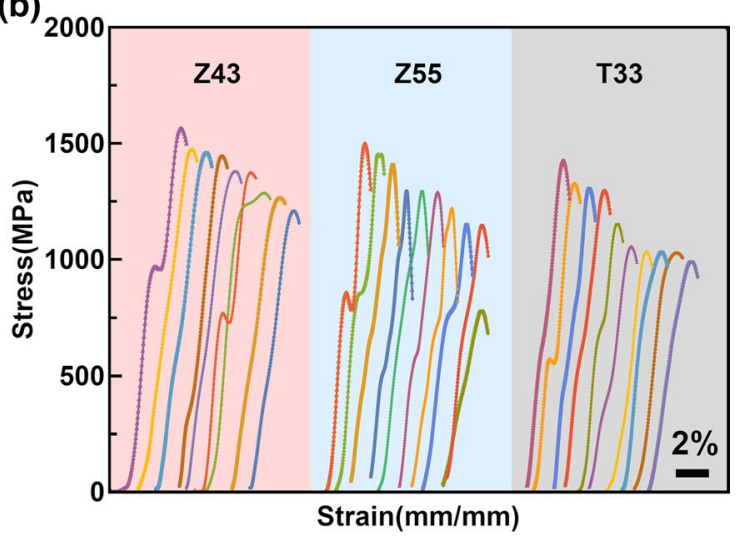

Fig. 4 Typical dynamic compressive strain-stress curves for the Z43, Z55 and T33 BMGs at the strain rate of $\mathbf{a} 500 \mathrm{~s}^{-1}, \mathbf{b}_{1000 \mathrm{~s}^{-1}}$ 

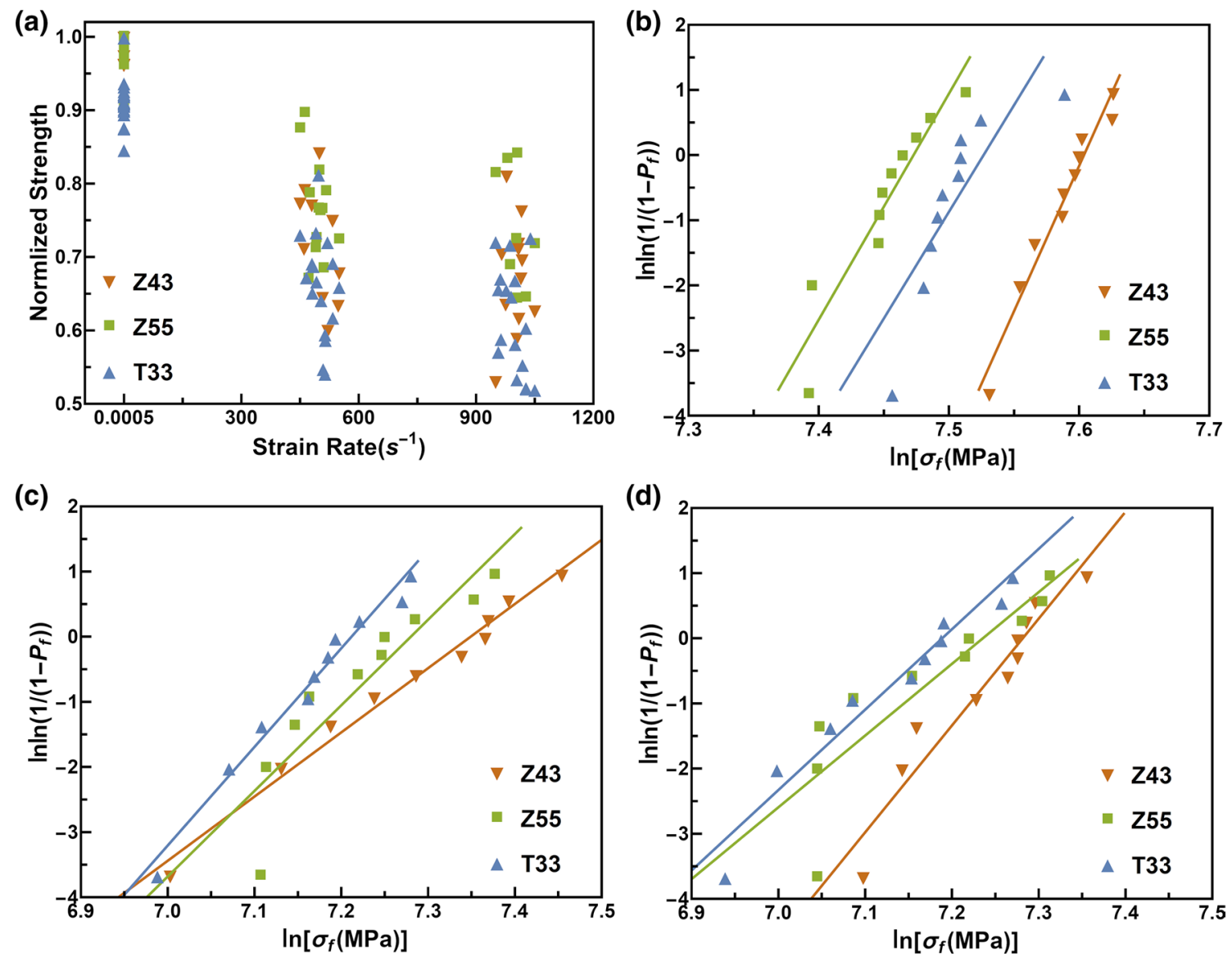

Fig. 5 a Normalized strength at the strain rate of $5 \times 10^{-4} \mathrm{~s}^{-1}, 500 \mathrm{~s}^{-1}, 1000 \mathrm{~s}^{-1}, \mathbf{b}-\mathbf{d}$ the corresponding two-parameter Weibull plots of strength for the Z43, Z55 and T33 BMGs

The scatter of strength with changing the strain rate was analyzed with the classical Weibull statistics [29-32], which is a well-established characterization method used for analyzing the fracture strength of brittle materials. The three-parameter distribution may in principle provide more accurate prediction than the two-parameter distribution. However, the parameters themselves are not as easily obtained and analytical calculations are usually no longer possible [32]. For this reason, we will use a two-parameter distribution in our following discussion.

For typical two-parameter Weibull probability of failure has the following form [32]:

$P_{\mathrm{f}}=1-\exp \left[-\left(\frac{\sigma}{\sigma_{0}}\right)^{m}\right]$

where $P_{\mathrm{f}}$ is the cumulative probability of failure at a given stress, $\sigma, m$ is the Weibull modulus (shape parameter or the flaw density parameter). The parameter $\sigma_{0}$, which has the dimensions of stress, is a scaling constant;

For $n$ nominally identical specimens of the same volume, the failure probability $P_{\mathrm{f}}$ of the $i$ th one is calculated using the following estimator [29], which is preferred among the various estimators used in the literature [30, 31],

$P_{\mathrm{f}, i}=\frac{i-0.5}{n}$.

Equation (1) can be linearized to the familiar form of the two-parameter solution, as listed

$\ln \ln \left(\frac{1}{1-P_{\mathrm{f}}}\right)=m \ln \sigma-m \ln \sigma_{0}$.

Figure 5b-d shows the resulting two-parameter Weibull plots of $\ln \ln \left(1 /\left(1-P_{\mathrm{f}}\right)\right)$ vs. $\ln \sigma$, linear regression fits to each data set results in two-parameter list in Table 1 . The value of $m$ indicates the degree of dispersion. As can be seen, in all cases, the data are in good linear fitting. This means that the experimental data are in agreement with the Weibull equation. 
Table 1 List of two-parameter Weibull modulus $(m)$ and the scaling stress $\left(\sigma_{0}\right)$ of three alloys at different strain rates

\begin{tabular}{llrl}
\hline Composition & Strain rate $\left(\mathrm{s}^{-1}\right)$ & $m$ & $\sigma_{0}(\mathrm{MPa})$ \\
\hline Z43 & $5 \times 10^{-4}$ & 42.2 & 2001 \\
Z55 & $5 \times 10^{-4}$ & 31.6 & 1753 \\
T33 & $5 \times 10^{-4}$ & 24.5 & 1850 \\
Z43 & 500 & 9.8 & 1536 \\
Z55 & 500 & 11.6 & 1439 \\
T33 & 500 & 14.4 & 1345 \\
Z43 & 1000 & 15.9 & 1442 \\
Z55 & 1000 & 10.9 & 1370 \\
T33 & 1000 & 11.8 & 1312 \\
\hline
\end{tabular}

\subsection{Fracture Morphology}

To find out why these BMG specimens show a strong dispersion in the dynamic compressive strengths, each fractured specimen was observed with SEM. In order to avoid the specimen fracturing into many fragments, the stopper ring was used, as shown in Fig. 1, which limits the maximum displacement less than $0.12 \mathrm{~mm}$. Accordingly, the original features were ensured in the fracture surface under dynamic compressions. The bigger fragment from the two fragments fractured from the dynamic specimen was observed in this work. Figure 6 shows the typical bigger fragments of the Z55 MG fractured at $500 \mathrm{~s}^{-1}$ and $1000 \mathrm{~s}^{-1}$.

It is indicated that the fracture of specimens is dominated by shear mode under dynamic compressions. It likes the fracture way of MG specimens in the quasi-static compression. The difference is that the fracture angle and fracture area are highly inconsistent among all the dynamic tests [13, 14, 25]. The strain rate has little effect on this phenomenon. A strong dispersion in the fracture angle and fracture area is also found out for the specimens fractured under dynamic compression loading. In addition, the fracture surfaces of the specimens fractured under dynamic and quasi-static loading show different features, as shown in Fig. 7. The fracture plane of the dynamically fractured specimens is more uneven than that of the quasi-statically fractured specimens, as shown in Fig. 7a, $d$, respectively. Several shear bands can be seen on the lateral surfaces near the fracture plane for both the specimens fractured quasi-statically and dynamically, as displayed in Fig. $7 b$, e, which indicate that the fracture mode is similar in the quasi-static and dynamic compressions, dominated by the fast propagation of single major shear band. The distribution of vein patterns is different on the quasi-static and dynamic fracture planes, as showed in Fig. 7c, f. Quasi-static vein patterns are flat and uniform, and larger in size, while in dynamic situations, the overall size of the vein patterns is small and different in size, with a lot of droplets on it. Whether quasi-static
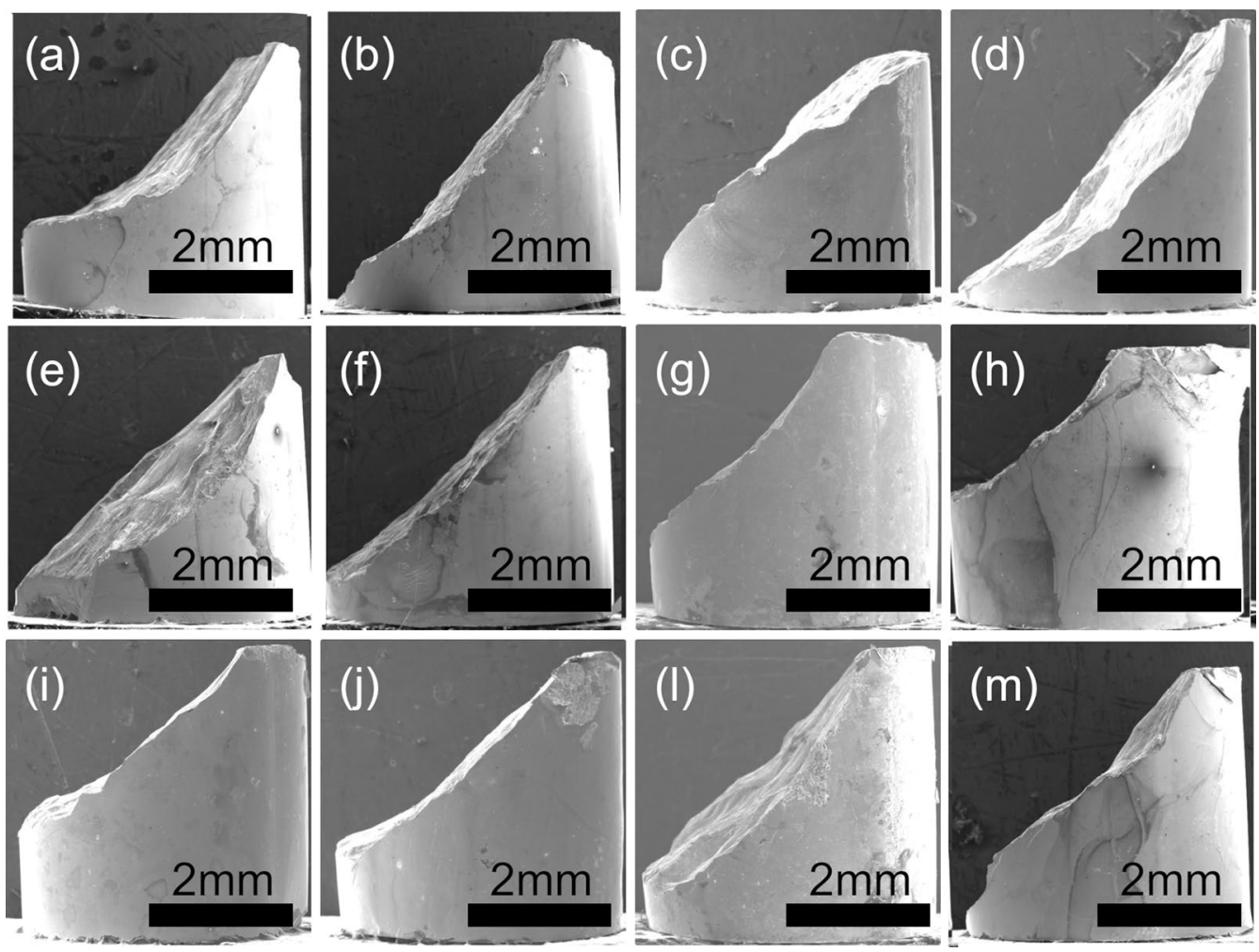

Fig. 6 Slide view of fractured Z55 at a-f $500 \mathrm{~s}^{-1}, \mathbf{g}-\mathbf{m} 1000 \mathrm{~s}^{-1}$ 

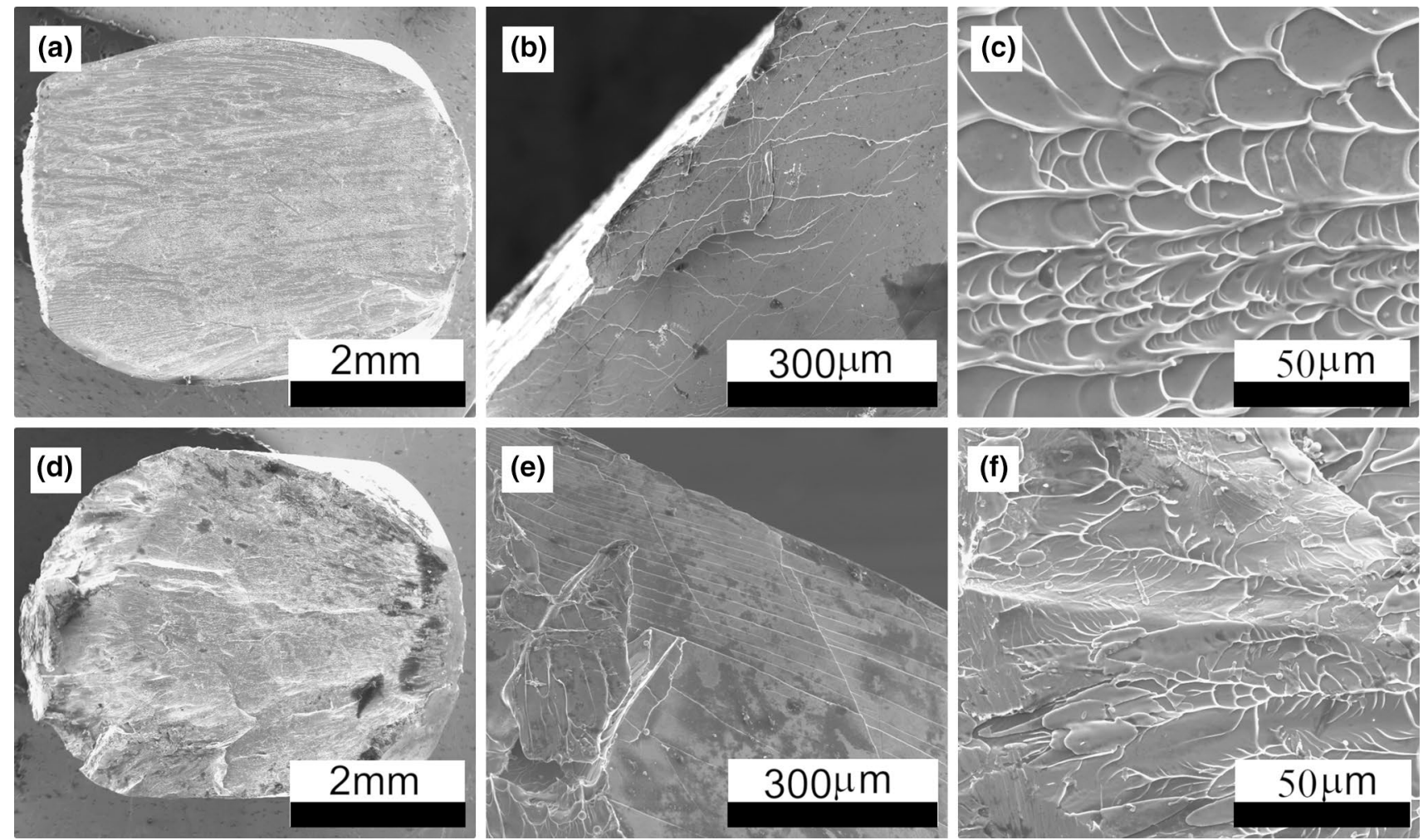

Fig. 7 Fracture morphologies of Z55 at $5 \times 10^{-4} \mathrm{~s}^{-1}(\mathbf{a}-\mathbf{c}), 500 \mathrm{~s}^{-1}(\mathbf{d}-\mathbf{f})$

or dynamic fracture, direction of the extended path of the shear surface and consistent with the development direction of the vein patterns.

\subsection{Correlation Between Strength and Fracture behaviors}

For quasi-static compression, the elastic energy $W_{\mathrm{E}}$ stored in a BMG sample upon failure can be expressed as [33]:

$W_{\mathrm{E}}=V_{0} \int_{0}^{\varepsilon_{\mathrm{f}}} \sigma \mathrm{d} \varepsilon$

where $V_{0}$ is Young's modulus and $\varepsilon_{\mathrm{f}}$ is the fracture strain of the BMG material.But for dynamic compression, $\mathrm{BMG}$ specimen absorbed energy can be calculated by following equation [34]:

$W_{\mathrm{E}}=W_{\mathrm{i}}-\left(W_{\mathrm{r}}+W_{\mathrm{t}}\right)$,

where $W_{\mathrm{E}}$ is the absorbed energy of BMG specimen; $W_{\mathrm{i}}$, $W_{\mathrm{r}}$ and $W_{\mathrm{t}}$ are energy carried by the incident, reflected and transmitted wave, respectively, which can be calculated by Eqs. (6-8)

$W_{\mathrm{i}}=\frac{A_{\mathrm{e}}}{\rho_{\mathrm{e}} c_{\mathrm{e}}} \int_{0}^{\tau} \sigma_{i}^{2}(t) \mathrm{d} t$
$W_{\mathrm{r}}=\frac{A_{\mathrm{e}}}{\rho_{\mathrm{e}} c_{\mathrm{e}}} \int_{0}^{\tau} \sigma_{r}^{2}(t) \mathrm{d} t$

$W_{\mathrm{t}}=\frac{A_{\mathrm{e}}}{\rho_{\mathrm{e}} c_{\mathrm{e}}} \int_{0}^{\tau} \sigma_{t}^{2}(t) \mathrm{d} t$,

where $\tau$ is the duration of stress wave; $\rho_{\mathrm{e}}$ is the density of bars; $c_{\mathrm{e}}$ is the elastic wave velocity of the bars; $A_{\mathrm{e}}$ is the cross-sectional area of the bars; $\sigma(t)$ denotes stress in bar at time $t$; and the subscripts $i, r$ and $t$ refer to the incident, reflected and transmitted wave, respectively.

The strain energy released during BMG fracture and failure is converted into several other types of energy, which are as follows: (1) fragmentation energy, $W_{\mathrm{G}}$, associated with the new fracture surface; (2) kinetic energy, $W_{\mathrm{K}}$, carried by ejected fragments; (3) other types of energy, $W_{\mathrm{O}}$, that mainly refer to radiant energy (electromagnetic energy and acoustic energy). The energy balance of BMG failure is shown in Eq. (9) [35]

$W_{\mathrm{E}}=W_{\mathrm{G}}+W_{\mathrm{K}}+W_{\mathrm{O}}$.

The energy partition is to some extent arbitrary and based on the final effects of fracture; however, in most cases, the radiant energy is negligible compared with other forms of energy, and the kinetic energy of ejected fragments 
accounts only for a comparatively small proportion of the total released strain energy [35], the proportion of conversion just depends on the loading rate under dynamic loads. Therefore, the total released strain energy is approximately equal to the fragmentation energy,

$W_{\mathrm{E}} \approx W_{\mathrm{G}}=G A_{\mathrm{n}}$,

where $A_{\mathrm{n}}$ is the area of new crack surfaces generated in BMG under quasi-static or dynamic loads; $G$ is the energy release rate. According to the fracture mechanics, energy release rate $G$ is also called the energy of fracture, $G$ is the energy required to create two new fracture surfaces and for ideally brittle materials is just $2 \gamma$, where $\gamma$ is the surface energy per unit area. Under plane strain, $G=K^{2} / E\left(l-\nu^{2}\right)$, where $K$ is the stress intensity $\left(\mathrm{MPa} \mathrm{m}^{1 / 2}\right)$ at fracture, and $\nu$ is Poisson's ratio. $K$ is constant with specific loading rate and sample size for a metallic glass.

For both quasi-static and dynamic loads, Eq. (10) [36] can be simplified that

$G A_{\mathrm{n}}=\eta \frac{\sigma_{\mathrm{F}}^{2}}{2 E} V_{0}$,

where $\sigma_{\mathrm{F}}$ is fracture strength of the BMG, $E$ is Young's modulus, $\eta$ is efficiency of stored elastic energy in creating the new surface during fracture, which depend loading rate and sample size.

In order to calculate the fracture surface area after dynamic fracture of the BMGs quantitatively, the fracture surface area is calculated using image processing software by SEM photos of fracture. Because fracture area change under quasi-static compression is small, we just show the dynamic results. The square of fracture strength $\sigma_{\mathrm{F}}^{2}$ and fracture surface area $A_{\mathrm{n}}$ are plotted, and the results of three amorphous alloys at two strain rates are drawn in Fig. 8, and the correlation coefficients of linear fitting are greater than 0.90 , which indicates that $\sigma_{\mathrm{F}}^{2}$ and $A_{\mathrm{n}}$ have good linear correlation. These findings show that the dispersion of dynamic strength is closely related to the fracture behaviors.

\subsection{High Dispersion of the Fracture Strength of the BMG Under Dynamic Deformation}

It is widely accepted that shear transformation zone (STZ) is the embryo of localized shear event in BMGs at atomicscale, and the yielding of BMGs corresponds to the unsteady propagation of a large number of STZs [37]. In a BMG specimen experiencing a uniform stress, it will be easier for the activation of STZ at the local regions with a higher free volume concentration [38], indicating a free volume softening effect on the yield strength. When the strain rate increases to larger than a critical value, the free volume concentration will be larger with increasing strain rate [23, 39],

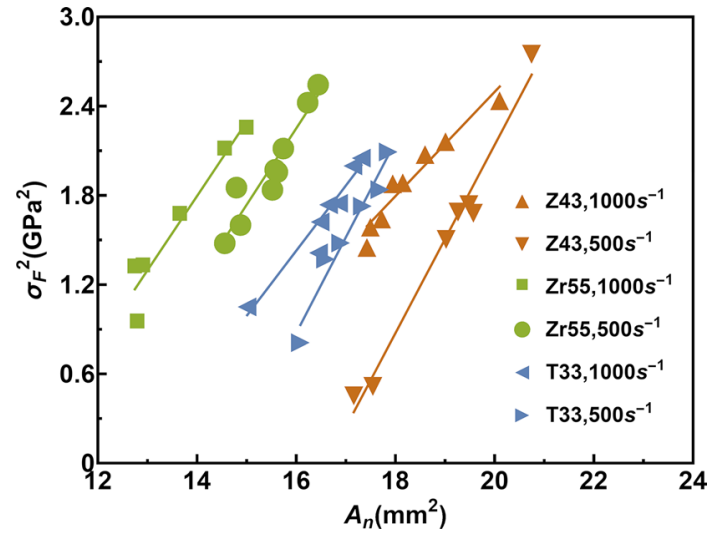

Fig. $8 \sigma_{\mathrm{F}}^{2}$ versus $A_{\mathrm{n}}$ of three alloys at $500 \mathrm{~s}^{-1}$ and $1000 \mathrm{~s}^{-1}$

which results in the negative dependence of the yielding strength on the strain rate. As for the quasi-static cases, both the weakly thermal fluctuation and the enough time for the reconstruction of the material in the shear band contribute to the repeated activation and arrest of the shear band, which eventually results in the relatively large plastic flow [23]. The initiation of the shear band under dynamic conditions is accompanied by a serious thermal softening, which will result in a significant decrease in material's viscosity in the shear band and then a reduction in the flow stress [40]. Consequently, there is a fast propagation of the shear band until the finally catastrophic failure. This is well consistent with the stress-strain curves presented in Figs. 3 and 4.

MGs are the typical low strain-to-failure materials under dynamic loading [25]. As shown in Fig. 4, almost all the strain exhibited for these materials corresponds to the elastic stress-strain regime. A significant stress concentration develops in the specimen using the SHPB experimental setup (cylindrical inserts and specimen) regardless of the specimen $L / D$ ratio. For an $L / D$ ratio of 1.0 , the stress concentration is $\sim 1.6$ [41]. That means that stress concentration in the sample using the SHPB experimental setup may cause premature failure, which leading the decrease in strength.

The premature failure of MGs is probably correlated with the random initiation of shear banding. According to the free volume model [38, 42], the initial free volume is heterogeneously distributed in the as-cast MG samples, and the regions with the enriched local free volume yield firstly, where the onset of shear localization and temperature rise will start. Finite element method (FEM) simulation result [43] showed that the free volume concentration permutation at different site is the place where shear band initiates, and if the free volume concentration of a sample is evenly distributed at different sites, the deformation is homogeneous and shear band cannot be obtained.

The actual distribution of free volume is significantly influenced by the practical cooling process in the as-cast 
samples. For example, in the solidification process of the as-cast samples, the cooling rate at the bottom is higher than at the top, and at the edges is higher than at the core. It is generally accepted that the higher the cooling rate, the richer the local free volume, which was well verified by Wang et al. [44]. Although this kind of heterogeneous distribution of free volume shows little influence of the average free volume, it may result into the heterogeneous distribution of free volume locally, which makes the randomness of shear band initiation, correspondingly leading to the different fracture behaviors under the dynamic loading. This speculation is confirmed by FEM simulation [45], which shows that the average free volume concentration of samples has significant effect on strength of the BMG in the quasi-static compression. The fracture strength of the BMG sample decreases with the increase in the average free volume concentration of sample. This decrease is more sensitive to the strain rate. The similar increase in average free concentration of a sample can produce the larger decrease in strength at high strain rate than at low strain rate [45].

In addition, the casting process unavoidably produces the casting defects such as porosity, shrinkage, gas rolling and cutting process defects in the as-cast BMG samples. These defects show a slight effect on the mechanical performance in the quasi-static compression but have a great significance on compressive strength under the dynamic loading. The existence of defects will produce the stress concentration, which leads to the initial position of the shear fracture randomly [26, 27]. It clearly leads to different fracture behaviors for MG specimens under dynamic compression. This explains the greater dispersion of compressive strength of the BMG at high strain rates than at quasi-static conditions in the current work.

\section{Conclusion}

All the three BMGs show a great dispersion on dynamic compressive strength and dynamic fracture behaviors at the same strain rate. It is found out that the square of dynamic compressive strength is proportional to the area of fracture surface, and both can be linearly fitted. All the specimens show the characteristics of shear fracture in the quasi-static and dynamic compression tests. The strong dispersion in the dynamic compressive strength is attributed to the difference of mean initial free volume concentration of different samples, stress concentration caused by SHPB experimental setup and high sensitivity of defects under dynamic deformation. These findings are significant for well understanding the relationship between the strain rate and fracture strength and further developing the high mechanical performance for BMGs.
Acknowledgements This work was financially supported by the National Natural Science Foundation of China (Nos. 51790484, U1738101), the National Key Research and Development Program (No. 2018YFB0703402), the Liaoning Revitalization Talents Program (Nos. XLYC1802078 and XLYC1807062), and the Shenyang Amorphous Metal Manufacturing Co., Ltd.

\section{References}

[1] M.F. Ashby, A.L. Greer, Scr. Mater. 54, 321 (2006)

[2] M. Chen, NPG Asia Mater. 3, 82 (2011)

[3] A. Inoue, A. Takeuchi, Acta Mater. 59, 2243 (2011)

[4] S. Lin, Z. Zhu, S. Ge, L. Zhang, D. Liu, Y. Zhuang, H. Fu, H. Li, A. Wang, H. Zhang, J. Mater. Sci. Technol. 50, 128 (2020)

[5] B. Zhao, Z. Zhu, X.D. Qin, Z. Li, H. Zhang, J. Mater. Sci. Technol. 46, $88(2020)$

[6] W.L. Johnson, MRS Bull. 24, 42 (1999)

[7] W.L. Johnson, JOM 54, 40 (2002)

[8] J. Plummer, W.L. Johnson, Nat. Mater. 14, 553 (2015)

[9] A. Inoue, N. Nishiyama, MRS Bull. 32, 651 (2007)

[10] J.Q. Li, L. Wang, H.W. Cheng, H.F. Zhang, Z.Q. Hu, H.N. Cai, J. Alloys Compd. 478, 827 (2009)

[11] S.A. Atroshenko, N.F. Morozov, W. Zheng, Y.J. Huang, Y.V. Sudenkov, N.S. Naumova, J. Shen, J. Alloys Compd. 505, 501 (2010)

[12] W. Ma, H. Kou, J. Li, H. Chang, L. Zhou, J. Alloys Compd. 472 214 (2009)

[13] R.D. Conner, R.B. Dandliker, V. Scruggs, W.L. Johnson, Int. J. Impact Eng. 24, 435 (2000)

[14] G. Subhash, R.J. Dowding, L.J. Kecskes, Mater. Sci. Eng. A 334, 33 (2002)

[15] G. Sunny, F. Yuan, V. Prakash, J. Lewandowski, J. Appl. Phys. 104, 093522 (2008)

[16] T.C. Hufnagel, T. Jiao, Y. Li, L.Q. Xing, K.T. Ramesh, J. Mater. Res. 17, 1441 (2002)

[17] H. Li, G. Subhash, X.L. Gao, L.J. Kecskes, R.J. Dowding, Scr. Mater. 49, 1087 (2003)

[18] T. Mukai, T.G. Nieh, Y. Kawamura, A. Inoue, K. Higashi, Intermetallics 10, 1071 (2002)

[19] G. Sunny, J. Lewandowski, V. Prakash, J. Mater. Res. 22, 389 (2007)

[20] D.G. Lee, Y.G. Kim, S. Lee, N.J. Kim, Metall. Mater. Trans. A 37, 2893 (2006)

[21] Y.F. Xue, H.N. Cai, L. Wang, F.C. Wang, H.F. Zhang, Mater. Sci. Eng. A 473, 105 (2008)

[22] F. Yang, Appl. Phys. Lett. 91, 051922 (2007)

[23] M.C. Li, M.Q. Jiang, S. Yang, F. Jiang, L. He, J. Sun, Mater. Sci. Eng. A 680, 21 (2017)

[24] H.A. Bruck, A.J. Rosakis, W.L. Johnson, J. Mater. Res. 11, 503 (1996)

[25] J. Fan, L. Yang, Int. J. Impact Eng. 106, 217 (2017)

[26] D. Zhou, B. Li, S. Zhang, B. Hou, Y. Li, Mater. Sci. Eng. A 730, $270(2018)$

[27] D. Zhou, B. Hou, B. Li, S. Zhang, L. Dai, Y. Li, Intermetallics 96, 94 (2018)

[28] B. Song, B.R. Antoun, X. Nie, W. Chen, Exp. Mech. 50, 553 (2010)

[29] Y.Y. Zhao, E. Ma, J. Xu, Scr. Mater. 58, 496 (2008)

[30] Z. Han, L.C. Tang, J. Xu, Y. Li, Scr. Mater. 61, 923 (2009)

[31] A. Bharathula, K.M. Flores, Acta Mater. 59, 7199 (2011)

[32] C.K.H. Dharan, B.S. Kang, I. Finnie, in Finnie's Notes on Fracture Mechanics. Fundamental and Practical Lessons, ed. by C.K.H. Dharan, B.S. Kang, I. Finnie (Springer, New York, 2016), pp. 215-249 
[33] B. Lawn, Fracture of Brittle Solids, 2nd edn. (Cambridge University Press, Cambridge, 1993)

[34] B. Lundberg, Int. J. Rock Mech. Min. Sci. Geomech. Abstr. 13, 187 (1976)

[35] Z.X. Zhang, S.Q. Kou, L.G. Jiang, P.A. Lindqvist, Int. J. Rock Mech. Min. Sci. 37, 745 (2000)

[36] Z.F. Zhang, H. Zhang, B.L. Shen, A. Inoue, J. Eckert, Philos. Mag. Lett. 86, 643 (2006)

[37] W.L. Johnson, K. Samwer, Phys. Rev. Lett. 95, 195501 (2005)

[38] A.S. Argon, Acta Metall. 27, 47 (1979)

[39] L.F. Liu, L.H. Dai, Y.L. Bai, B.C. Wei, J. Non Cryst. Solids 351, $3259(2005)$
[40] A.J. Cao, Y.Q. Cheng, E. Ma, Acta Mater. 57, 5146 (2009)

[41] G. Sunny, F. Yuan, V. Prakash, J. Lewandowski, Exp. Mech. 49 , 479 (2008)

[42] P.S. Steif, F. Spaepen, J.W. Hutchinson, Acta Metall. 30, 447 (1982)

[43] Y.F. Gao, Model. Simul. Mater. Sci. Eng. 14, 1329 (2006)

[44] Z.H. Wang, Z.M. Jiao, L. Cheng, G.S. Xiao, J.Q. Wang, S.G. Ma, H.J. Yang, J.W. Qiao, J. Non Cryst. Solids 441, 29 (2016)

[45] J.C. Li, Q. Wei, X.W. Chen, F.L. Huang, Mater. Sci. Eng., A 610, 91 (2014) 